\section{Por que o Brasil ainda registra elevados coeficientes de transmissão vertical do HIV? Uma avaliação da qualidade da assistência prestada a gestantes / parturientes infectadas pelo HIV e seus recém-nascidos}

\section{Why does Brazil still report high rates of vertical HIV transmission? An evaluation of health care quality to HIV-infected pregnant women and their children}

Ana Lucia Ribeiro de Vasconcelos 1 Edgar Merchán Hamann 2

${ }^{1}$ Ministério da Saúde. Secretaria de Vigilância em Saúde. Programa Nacional de DST e AIDS. Unidade de Assistência e Tratamento. SEPN 511, Bloco C, 20 andar. Asa Norte. Brasília, DF, Brasil. CEP: 70.750 543. Fone: (61) 34488071 Fax: (61) 34488057 2 Núcleo de Estudos de Saúde Pública. Centro de Estudos Avançados Multidisciplinares. Universidade de Brasília. Brasília, DF, Brasil.

\begin{abstract}
Objectives: to assess the health care provided to $H I V+$ pregnant women and their children and determine vertical transmission rates in four Brazilian capitals.

Methods: a cohort study was performed in a population of 1475 HIV+pregnant women and their children, who received health care between 1996 and 2003, in 17 public maternities. Data were collected retrospectively from clinical records and 274 women were interviewed (prospective phase) based on a structured questionnaire.

Results: regarding quality of health care, it was verified in the retrospective and prospective phases of the study, respectively, that $24 \%$ and $27 \%$ of women did not even receive oral $A Z T ; 19 \%$ and $10 \%$ did not receive intravenous $A Z T ; 8 \%$ and $7 \%$ of babies did not receive oral AZT. The vertical transmission rate was $5,6 \%$ varying from $2,9 \%$ to $7,5 \%$ between cities and being higher in vaginal delivers (8\%) and nonelective caesarian section (7\%).

Conclusions: Brazilian Program for Reducing HIV Vertical Transmission is vulnerable due to the lack of organization, administration and evaluation in the health services. A model-guidance is suggested with steps necessary for a better understanding in all levels of these managerial steps.
\end{abstract}

Key words HIV, Disease transmission, vertical, Pregnancy; Prenatal care, Program evaluation, Parturition

\section{Resumo}

Objetivos: avaliar a assistência prestada a parturientes HIV+e seus recém-nascidos (RN), e determinar os coeficientes de transmissão vertical (TV) do HIV em quatro capitais brasileiras.

Métodos: foi realizado um estudo de coorte cuja população correspondeu a 1475 parturientes HIV+e seus RN, assistidas de 1996 a 2003, em 17 maternidades públicas. As informações foram obtidas, retrospectivamente, a partir dos prontuários médicos e de um questionário estruturado (fase prospectiva) aplicado em 274 mulheres.

Resultados: quanto à assistência dispensada, verificou-se respectivamente nas fases retrospectiva $e$ prospectiva do estudo, que cerca de $24 \%$ e $27 \%$ das gestantes não tiveram acesso sequer ao AZT oral; $19 \%$ e $10 \%$ das parturientes não receberam o AZT intravenoso; $8 \%$ e $7 \%$ dos bebês não foram medicados com o AZT solução oral. O coeficiente de TV foi de 5,6\% variando de 2,9\% a 7,5\% nas cidades, e sendo maior no parto vaginal (8\%) e na cirurgia cesariana não-eletiva (7\%).

Conclusões: o Programa Brasileiro de Redução da $T V$ do HIV se revela frágil no que diz respeito à sua organização, administração e avaliação nos serviços de saúde. Para melhor entendimento dessas etapas, nos vários níveis de gestão, um modelo-guia é sugerido.

Palavras-chave HIV, Transmissão vertical de doença, Gravidez, Cuidado pré-natal, Avaliação de Programas, Parto 


\section{Introdução}

Com base nos resultados das pesquisas realizadas, que visam à identificação dos fatores de risco para a transmissão vertical do HIV e às medidas que promovem sua preven-ção,1-7 o Brasil vem adotando, em sua política de prevenção e controle da epidemia de AIDS, reco-mendações cujos objetivos são o controle da doença materna e, conseqüentemente, a redução da transmissão vertical do HIV. A primeira publicação do Ministério da Saúde contendo recomendações para profilaxia da transmissão vertical do HIV data de $1995,{ }^{8}$ e foi baseada nos resultados do Paediatric AIDS Clinical Trial Group (PACTG), protocolo 076.1 Em 1996, a Lei Federal 9.313 de 13/11/1996 passou a garantir aos portadores de HIV, com indicação terapêutica conforme os critérios estabelecidos pelo consenso terapêutico brasileiro, acesso gratuito e universal à terapia anti-retroviral (TARV). A partir de 1998, o consenso terapêutico de TARV para adultos e adolescentes 10 já incluía a possibilidade de uso dessa terapia combinada em gestantes. É importante ressaltar que o AZT intravenoso já estava disponível na rede, com orientação de uso, desde 1996; e o AZT oral, desde 1991, com produção nacional a partir de 1993. O parto por cesariana eletiva foi incluído nas recomendações desse mesmo consenso terapêutico, 10 sem, no entanto, estabelecer critérios para sua indicação.

Quanto à contra-indicação do aleitamento materno e do aleitamento materno cruzado (amamentação da criança por outra mulher), já estava presente nas recomendações brasileiras de 1995.8

Em 2001, o Ministério da Saúde constituiu um comitê assessor que tem por atribuição específica incorporar à política brasileira recomendações de uso de TARV em gestantes e outras diretrizes para a redução da transmissão vertical do HIV, em que riscos e benefícios materno-fetais são considerados e balanceados. ${ }^{11} \mathrm{Com}$ isso, a partir desse ano, ficou estabelecido no Brasil o uso de TARV potente (AZT combinado a dois outros ARV) em gestantes, de acordo com os resultados da avaliação do estado clínico e dos exames de contagem do número de linfócitos T-CD4+ e de quantificação da carga viral da gestante. Estabeleceu-se também, nesse momento, os critérios para a definição da via de parto com base nos níveis de carga viral materna aferidos a partir da 34a semana de gestação. Ou seja, o parto por cirurgia cesariana eletiva passou a ter parâmetros de indicação precisos, estabelecendo-se essa via de parto a partir de então, sempre que a carga viral materna no sangue fosse igual ou maior que 1000 cópias/ml, ou desconhecida. ${ }^{11}$

O conceito de cirurgia cesariana eletiva (CCE) se aplica àquela em que a intervenção cirúrgica é programada e realizada antes do início do trabalho de parto, encontrando-se as membranas amnióticas íntegras. Nessas condições ideais, de verdadeira proteção ao recém-nascido exposto ao HIV,12 a administração da quimioprofilaxia com o AZT intravenoso deverá ter início três horas antes da intervenção, a fim de possibilitar proteção da criança ao HIV. Reconhecendo os benefícios conferidos pela cesariana $5,7,12$ e, sabendo das dificuldades operacionais da rede de saúde, as recomendações do Ministério da Saúde ampliam a indicação de CCE para o grupo de mulheres que chegam à maternidade com as membranas amnióticas íntegras e dilatação cervical em até 3 a $4 \mathrm{~cm} .11,13$

O objetivo deste estudo foi analisar, utilizando os prontuários médicos como fonte de informações, a qualidade da assistência prestada a gestantes/ parturientes portadoras do HIV e seus recémnascidos, focalizando aspectos essenciais da mesma. Buscou-se também verificar o coeficiente de incidência de HIV nos recém-nascidos segundo a via de parto, local e ano do parto.

\section{Métodos}

Trata-se de um estudo epidemiológico analítico de coorte, com componentes prospectivo e retrospectivo. A população de estudo foi composta por mulheres infectadas pelo HIV durante o ciclo gravídicopuerperal e seus recém-nascidos. As maternidades foram os serviços escolhidos para a coleta de informações, por estarem no ponto central do contexto da rede de serviços que deverá servir como referência para essa população. Aceitaram participar do estudo 17 maternidades públicas reconhecidas pelas coordenações locais de DST/AIDS como serviços de referência para o parto de mulheres infectadas pelo HIV e crianças expostas, situadas em quatro capitais brasileiras, uma por região. As regiões representadas são: Sudeste (Cidade 1), Nordeste (Cidade 2); Sul (Cidade 3) e Centro-Oeste (Cidade 4). Por problemas operacionais, nenhuma capital da região Norte participou do estudo. Partiu-se do pressuposto que as capitais escolhidas, por representarem realidades epidemiológicas e operacionais semelhantes às encontradas em qualquer uma das grandes cidades brasileiras, gerem informações quanto às falhas existentes, perfeitamente passíveis de correção em curto prazo, pela observância da "Linha do Cuidado" preconizada pelo Ministério da Saúde para essa 
população. Foi chamada "Linha do Cuidado" ao conjunto de recomendações preconizadas pelo Ministério da Saúde13 para assistência da população objeto do estudo, ou seja, a observância da realização dos exames laboratoriais no pré-natal; da TARV indicada de acordo com essa avaliação, o estado clínico e a idade gestacional da paciente; da adequação da via de parto segundo os níveis da carga viral materna aferida próximo ao parto; do número mínimo de consultas que se faz necessário para que a vigilância dessas mulheres seja adequada; e dos cuidados preconizados para essa população durante o trabalho de parto, no parto propriamente dito e com o recém-nascido.

Ao todo, participaram do estudo 1.475 parturientes infectadas pelo HIV e seus recém-nascidos, assistidas de janeiro de 1997 a dezembro de $2002 \mathrm{em}$ maternidades da Cidade 1, e de janeiro de 1997 a dezembro de 2003, em maternidades das Cidades 2, 3 e 4 . As informações foram coletadas a partir dos prontuários médicos, no período acima mencionado, utilizando-se um instrumento com 54 perguntas (componente retrospectivo).

Sabendo-se das precárias condições de preenchimento dos prontuários médicos, durante o período de seis meses em que estavam ocorrendo os levantamentos de dados nas instituições incluídas no estudo, foi feita uma entrevista com puérperas infectadas pelo HIV assistidas nessas maternidades (componente prospectivo). Aceitaram ser entrevistadas 274 mulheres, que representam $18,6 \%$ do total da amostra. Para isso, foi utilizado um questionário estruturado, contendo 48 perguntas, das quais 27 correspondiam às mesmas informações do instrumento de coleta dos prontuários médicos.

Para conhecer o diagnóstico das crianças expostas participantes do estudo, realizou-se um rastreamento de crianças nascidas de mães infectadas pelo HIV, acompanhadas no serviço de referência localizado no complexo hospitalar da maternidade onde a criança nasceu, quando o mesmo existia. Foi também realizada busca ativa nos outros serviços especializados na cidade onde ocorreu o parto da criança. Nas duas situações foi utilizada a infraestrutura que esses serviços possuem. Com isso, foi possível documentar o conhecimento da organização do sistema local em relação às crianças incluídas no estudo.

As principais variáveis objeto de nossa análise são: a implementação do diagnóstico de HIV ao longo do período (1996-2003); o momento do diagnóstico da infecção pelo HIV das mães e o número de consultas realizadas no pré-natal; a TARV usada durante a gestação, no parto e pelo recém-nascido; a duração do trabalho de parto e o tempo de ruptura das membranas amnióticas; a via de parto; as condições da criança ao nascer (Apgar ${ }^{14}$ e peso ao nascer) e o tipo de alimento fornecido ao recémnascido. Foram documentadas as proporções de falta das informações nos prontuários médicos e de perdas do seguimento das crianças, pois tais dados complementam a avaliação da qualidade da assistência.

Neste estudo foram classificados como CCE os partos cirúrgicos que ocorreram nas condições de indicação ampliada do consenso terapêutico brasileiro, e quando essa via de parto não teve sua indicação imposta por condições obstétricas de risco para a mãe e/ou o recém-nascido. Havendo a presença dessa última condição e/ou a ausência das referidas no conceito ampliado para a CCE, o parto cirúrgico, no presente estudo, foi classificado como sendo por intervenção cesariana não-eletiva (CCNE). Foram classificados na categoria de parto vaginal (PV) todos aqueles ocorridos por essa via de parto, independentemente das condições em que se processaram.

Foi calculada a proporção de cada variável categórica e o coeficiente de incidência da transmissão vertical, e descrita sua distribuição segundo cidade e tipo de parto.

O protocolo de pesquisa foi submetido ao Comitê de Ética em Pesquisa, da Faculdade de Ciências da Saúde da Universidade de Brasília e foi aprovado no dia 25 de junho de 2002.

\section{Resultados}

Os resultados obtidos no total da amostra (dados coletados a partir dos prontuários médicos ou componente retrospectivo do estudo), representados por 1.475 pares de mães infectadas pelo HIV e seus bebês, e dos fornecidos pela entrevista com 274 puérperas participantes do estudo, revelam ter havido aumento no diagnóstico anti-HIV ao longo do período. Os resultados fornecidos, respectivamente, pelos prontuários médicos e pelas entrevistas, foram: antes de 1996 havia, respectivamente, apenas $99(7 \%)$ e 11 (4\%) mulheres diagnosticadas; no período compreendido entre 1996 a 1999 foram diagnosticadas, respectivamente, 449 (30\%) e 25 (9\%) mulheres; e no período entre 2000 a 2003 houve, respectivamente, $630(43 \%)$ e $193(70 \%)$ mulheres diagnosticadas. Tal informação estava faltando em 297 (20\%) prontuários médicos e em 45 (16\%) (das) entrevistas.

Quanto ao momento de diagnóstico da mãe (Tabela 1), os resultados dos prontuários médicos 
Momento do diagnóstico de HIV da mãe e terapia anti-retroviral (TARV) usada pelas gestantes, parturientes e seus recém-nascidos, em maternidades públicas de quatro capitais brasileiras, 1997 a 2003.

\begin{tabular}{|c|c|c|c|c|}
\hline & \multicolumn{2}{|c|}{ Total da amostra } & \multicolumn{2}{|c|}{ Entre as entrevistadas } \\
\hline & $\mathrm{n}$ & $\%$ & $\mathrm{n}$ & $\%$ \\
\hline \multicolumn{5}{|c|}{ Momento do diagnóstico de HIV da mãe } \\
\hline Antes da gestação & 512 & 34,8 & 117 & 42,7 \\
\hline Durante a gestação & 670 & 45,4 & 129 & 47,1 \\
\hline Na maternidade: & 157 & 10,6 & 24 & 8,7 \\
\hline Antes do parto & 60 & 4,1 & 20 & 7,3 \\
\hline Após o parto & 97 & 6,5 & 4 & 1,4 \\
\hline Logo após o parto & 14 & 0,9 & 2 & 0,7 \\
\hline Dias após o parto & 83 & 5,6 & 2 & 0,7 \\
\hline Sem informação & 136 & 9,2 & 4 & 1,5 \\
\hline \multicolumn{5}{|c|}{ Uso de TARV pelas gestantes } \\
\hline Usou & 1015 & 69 & 187 & 68,2 \\
\hline Apenas o AZT oral & 446 & 30 & 40 & 14,6 \\
\hline TARV combinada & 569 & 39 & 147 & 53,6 \\
\hline Não usou & 359 & 24 & 75 & 27,4 \\
\hline Sem informação & 101 & 7 & 12 & 4,4 \\
\hline \multicolumn{5}{|c|}{ Uso de profilaxia, com AZT intravenoso, pelas parturientes } \\
\hline Usou & 1142 & 77,4 & 233 & 85,0 \\
\hline Não usou & 282 & 19,1 & 28 & 10,2 \\
\hline Sem informação & 51 & 3,5 & 13 & 4,7 \\
\hline \multicolumn{5}{|c|}{ Uso de profilaxia, com AZT solução oral, pelos recém-nascidos } \\
\hline Usou & 1329 & 90,1 & 239 & 87,2 \\
\hline Não usou & 112 & 7,6 & 19 & 6,9 \\
\hline Sem informação & 34 & 2,3 & 16 & 5,9 \\
\hline Total & 1475 & 100,0 & 274 & 100,0 \\
\hline
\end{tabular}

demonstraram que em $80 \%$ dos casos o diagnóstico de HIV ocorreu antes do parto. Nas maternidades foram diagnosticadas $157(11 \%)$ mulheres. Todavia, foi em apenas 60 (4\%) parturientes que esse diagnóstico se deu antes do parto, e, dentre as diagnosticadas após o parto, esse momento para a grande maioria ocorreu dias após o parto. Entre as entrevistadas, esse diagnóstico ocorreu antes do parto em $90 \%$ das mulheres, e a maternidade foi a ocasião do diagnóstico para $24(9 \%)$ mulheres, ocorrendo esse diagnóstico antes do parto em 20 (7\%) dessas parturientes.

Quanto ao uso de TARV pelas mulheres gestantes, parturientes, e por seus recém-nascidos (Tabela 1), destaca-se nos resultados provenientes dos prontuários médicos que 359 mulheres (24\%) não usaram sequer o AZT durante sua gestação; 282 parturientes (19\%) não foram medicadas com o AZT intravenoso; e 112 bebês ( $8 \%$ ) não foram medicados com o AZT solução oral. Quanto ao uso de TARV combinada, fizeram uso apenas 569 gestantes (39\% do total da amostra). Entre as entrevistadas houve os seguintes resultados: não usaram sequer o AZT oral $75(27 \%)$ gestantes; o AZT intravenoso não foi administrado em 28 (10\%) parturientes; e não receberam o AZT solução oral $19(7 \%)$ crianças. A TARV combinada foi usada por $147(54 \%)$ gestantes.

Quanto ao número de consultas de pré-natal realizadas pelas mulheres, os resultados obtidos revelaram: no total da amostra, 145 gestantes $(10 \%)$ não haviam feito pré-natal; apenas 125 (8\%) completaram quatro consultas (o mínimo preconizado pela Organização Mundial da Saúde (OMS) para os países com escassez de médicos/enfermeiros);15 198 (13\%) realizaram seis consultas (o mínimo preco- 
nizado pelo Ministério da Saúde para gestante sem risco - Programa de Humanização no Pré-natal e Nascimento - PHPN); 16 a minoria representada por 16 gestantes ( $1 \%$ dos casos) realizaram 10 ou mais consultas no pré-natal (o número de consultas esperadas para essa população de gestantes) ${ }^{17}$ Entre as entrevistadas, os resultados obtidos foram: 14 gestantes $(5 \%)$ não haviam realizado o pré-natal; 31 (11\%) realizaram até quatro consultas; 38 (14\%) completaram seis; e 30 gestantes $(11 \%)$ realizaram 10 ou mais consultas no pré-natal. Não havia essa informação em 94 fichas (6\%) analisadas do total da amostra e em 4 (1,5\%) das entrevistas.

Com relação às condições em que o parto ocorreu, dois aspectos foram analisados: as condições das membranas amnióticas e a duração do trabalho de parto (Tabela 2). No total da amostra, as membranas estavam íntegras até o parto em apenas 794 parturientes (54\%), estando aqui representadas as mulheres que foram submetidas à operação cesariana eletiva ou ao parto vaginal impelicado (quando ocorre o rompimento das membranas após a expulsão do recém-nascido). Entre as que estiveram com as bolsas rotas, apenas 261 parturientes $(18 \%)$ as tiveram por até quatro horas; 161 parturientes $(11 \%)$ apresentaram período de ruptura maior que quatro horas. Como pode ser visto na Tabela 2, os resultados foram semelhantes entre as entrevistadas.

Quanto à duração do trabalho de parto, em apenas 429 mulheres (29\%) esta foi de até seis horas. Os partos demandaram de seis a 24 horas em 264 (18\%) parturientes e de 24 a 72 horas em 17 (1\%) parturientes. Não havia essa informação em 182 (12\%) prontuários médicos.

Quanto às condições da criança ao nascer, foram analisadas as informações do Apgar no $5^{\circ}$ minuto pós-parto e o peso ao nascer (Tabela 3). Com relação à classificação de Apgar, 64 (4\%) crianças apresentaram ao nascer algum grau de asfixia e quanto às condições do peso ao nascer, 276 (19\%) recémnascidos (RN) nasceram dentro dos parâmetros de classificação de "RN de risco" (<2.500g).

A análise dos dados relativos ao tipo de leite que foi ofertado às crianças durante sua permanência na maternidade revelou que $155(10 \%)$ recém-nascidos foram expostos ao risco adicional de transmissão do HIV no pós-parto pela amamentação. Dentre esses, duas crianças $(0,1 \%)$ foram submetidas à amamentação cruzada (quando a criança é aleitada por outra mulher, havendo ou não, no período, amamentação pela mãe biológica). Receberam a fórmula infantil desde o nascimento 1.229 crianças (83\%) e 43 (3\%) foram alimentadas com leite humano pasteurizado, fornecido pelo Banco de Leite da instituição. Essa
Tabela 2

Caracterização da morbidade por diarréia em crianças com idade entre um ano completo e cinco anos incompletos.

\begin{tabular}{|c|c|c|}
\hline & \multicolumn{2}{|c|}{ Total da amostra } \\
\hline & $\mathrm{n}$ & $\%$ \\
\hline Integras (CCE e PV impelicado) & 794 & 53,8 \\
\hline Rotas, até 4 horas & 261 & 17,7 \\
\hline Rotas, por mais de 4 a 8 horas & 80 & 5,4 \\
\hline Rotas, por mais de 8 a 12 horas & 41 & 2,8 \\
\hline Rotas, por mais de 12 a 72 horas & 40 & 2,7 \\
\hline Sem informação & 259 & 17,6 \\
\hline \multirow[t]{3}{*}{ Total } & 1475 & 100,0 \\
\hline & \multicolumn{2}{|c|}{ Entre as entrevistadas } \\
\hline & $\mathrm{n}$ & $\%$ \\
\hline Integras (CCE) / Rompidas no período expulsivo & 140 & 51,1 \\
\hline Rotas antes do parto & 74 & 27,0 \\
\hline Sem informação & 60 & 21,9 \\
\hline Total & 274 & 100,0 \\
\hline
\end{tabular}

$\mathrm{CCE}=$ cirurgia cesariana eletiva; $\mathrm{PV}=$ parto vaginal

Tabela 3

Caracterização da morbidade por diarréia em crianças com idade entre um ano completo e cinco anos incompletos.

Crianças expostas ao HIV

\begin{tabular}{|c|c|c|}
\hline & $\mathrm{n}$ & $\%$ \\
\hline \multicolumn{3}{|l|}{ Classificação de Apgar no 5 minuto } \\
\hline 0 - 2 (asfixia severa) & 4 & 0,3 \\
\hline 3 - 4 (asfixia moderada) & 7 & 0,4 \\
\hline 5 - 7 (asfixia leve) & 53 & 3,6 \\
\hline $8-10$ (sem asfixia) & 1.338 & 90,8 \\
\hline Sem informação & 73 & 4,9 \\
\hline \multicolumn{3}{|l|}{ Peso ao nascer } \\
\hline Abaixo de $1000 \mathrm{~g}$ (extremo baixo peso) & 11 & 0,8 \\
\hline Entre $1000 \mathrm{~g}$ e $1499 \mathrm{~g}$ (muito baixo peso) & 24 & 1,6 \\
\hline Entre $1500 \mathrm{~g}$ e $2499 \mathrm{~g}$ (baixo peso) & 241 & 16,3 \\
\hline Entre $2500 \mathrm{~g}$ e $2999 \mathrm{~g}$ (peso insuficiente) & 467 & 31,7 \\
\hline Entre $3000 \mathrm{~g}$ e $3999 \mathrm{~g}$ (peso normal) & 667 & 45,2 \\
\hline Acima de $4000 \mathrm{~g}$ (sobrepeso) & 41 & 2,8 \\
\hline Sem informação & 24 & 1,6 \\
\hline Total & 1475 & 100,0 \\
\hline
\end{tabular}


Coeficientes de transmissão vertical do HIV, em maternidades públicas de quatro capitais brasileiras, segundo cidade participante, no período de 1997 a 2003.

\begin{tabular}{|c|c|c|c|c|c|c|c|}
\hline \multirow{3}{*}{ Variáveis } & \multicolumn{6}{|c|}{ Crianças expostas ao HIV } & \multirow{3}{*}{$\begin{array}{l}\text { Coeficiente de } \\
{ }^{*} \text { TV do HIV (\%) }\end{array}$} \\
\hline & \multirow{2}{*}{$\begin{array}{c}\begin{array}{c}\text { Total } \\
\text { da amostra }\end{array} \\
\mathrm{N}\end{array}$} & \multirow{2}{*}{$\begin{array}{c}\text { Crianças } \\
\text { não-infectadas } \\
\mathrm{n}\end{array}$} & \multirow{2}{*}{$\begin{array}{c}\begin{array}{c}\text { Crianças } \\
\text { infectadas }\end{array} \\
n\end{array}$} & \multirow{2}{*}{$\begin{array}{c}\text { Natimortos }+ \\
\text { Óbitos neonatais } \\
\mathrm{n}\end{array}$} & \multicolumn{2}{|c|}{$\begin{array}{l}\text { Perdas de } \\
\text { seguimento }\end{array}$} & \\
\hline & & & & & $\mathrm{n}$ & $\%$ & \\
\hline Cidade 1 & 796 & 313 & 17 & 19 & 447 & 56,15 & 5,15 \\
\hline Cidade 2 & 187 & 119 & 7 & 3 & 58 & 31,02 & 5,55 \\
\hline Cidade 3 & 389 & 197 & 16 & 5 & 171 & 43,96 & 7,51 \\
\hline Cidade 4 & 103 & 99 & 3 & 1 & & 0 & 2,94 \\
\hline Total & 1475 & 728 & 43 & 28 & 676 & 45,83 & 5,58 \\
\hline
\end{tabular}

*TV $=$ transmissão vertical

Tabela 5

Coeficientes de transmissão vertical do HIV, em maternidades públicas de quatro capitais brasileiras, segundo cidade participante, no período de 1997 a 2003.

\begin{tabular}{|c|c|c|c|c|c|}
\hline Tipo de parto & \multicolumn{2}{|c|}{ Total da amostra } & Crianças com diagnóstico & Crianças & $\begin{array}{l}\text { Coeficiente de } \\
\text { **TV do HIV (\%) }\end{array}$ \\
\hline & $\mathrm{n}$ & $\%$ & $\mathrm{n}$ & $\mathrm{n}$ & \\
\hline CCNE & 229 & 15,52 & 127 & 9 & 7,09 \\
\hline PV & 660 & 44,75 & 297 & 25 & 8,42 \\
\hline Sem informação & 3 & 0,20 & 2 & & \\
\hline Total & 1475 & 100,0 & 771 & 43 & 5,58 \\
\hline
\end{tabular}

* Número de crianças não-infectadas+ número de crianças infectadas; CCE = cirurgia cesariana eletiva; CCNE = cirurgia cesariana não-eletiva; $P V=$ parto vaginal. ** TV $=$ transmissão vertical

informação não estava disponível em 48 (3\%) dos prontuários médicos. Entre as entrevistadas, foram obtidas as seguintes informações: aleitaram seus bebês cinco (2\%) mulheres e duas, entre essas mulheres, deixaram seus bebês serem amamentados por outra mulher. Informaram que não amamentaram seus bebês 257 (94\%) mulheres, e não possuíam informação 12 (4\%) questionários.

Com relação ao diagnóstico das crianças expostas ao HIV (Tabela 4), foi possível conhecer o diagnóstico de apenas 771 (52\%): obtiveram o diagnóstico de não-infectadas 728 crianças, e de infectadas, 43 crianças. O coeficiente global de Transmissão Vertical foi de 5,58\%, sendo verificada variação entre as cidades-capitais participantes do estudo. Analisando tal coeficiente por ano de nascimento, observa-se que houve uma diminuição considerável no decorrer do período, caindo, da obtida em 1997 (14,3\%), para 3,7\% em 2003, tendo sido verificada uma diminuição estatisticamente significativa entre o início das estratégias de intervenção para prevenção dessa transmissão e o último ano do estudo $(\mathrm{RR}=3,9$; $\mathrm{IC} 95 \%=1,4-10,9 ; p=$ 0,01).

Como pode ser observado na Tabela 5, houve variação nos coeficientes de transmissão vertical segundo o tipo de parto, sendo maior por parto vaginal (PV) em relação à CCE e tal diferença foi estatisticamente significante $(\mathrm{RR}=3,2$; IC $95 \%=$ $1,5-6,8 ; p=0,001)$. Em relação à $\mathrm{CCNE}$, foi verificado também um maior risco de transmissão quando comparado com a CCE (RR = 2,7; IC 95\% = 1,1-6,7; $p=0,03)$. E essa variação foi observada em todas as cidades participantes do estudo, apresentando os 
seguintes resultados: na cidade 1 , o coeficiente de transmissão vertical entre os que nasceram por CCE foi de $2,5 \%$, sendo de $5,7 \%$ no parto pela CCNE, e de $7,2 \%$ no PV. Na cidade 2 , o coeficiente de transmissão vertical entre os que nasceram por CCE foi de $2,3 \%$, e de $6,2 \%$ e $17,4 \%$, respectivamente, entre as crianças nascidas por meio da CCNE e pelo PV. Na cidade 3, o coeficiente entre os nascidos por CCE foi de 5,4\%, nos nascidos por meio da CCNE foi de $7,9 \%$, e de $8,9 \%$ entre os que nasceram por PV; e na cidade 4 , o coeficiente de transmissão entre as crianças que nasceram pela CCE foi $0 \%$, entre os que nasceram pela CCNE, de $10 \%$, e entre os que nasceram por PV, de 5\%. Nas cidades 1,2 e 3 o parto vaginal apresentou os maiores coeficientes de transmissão vertical, seguido da cirurgia cesariana nãoeletiva. Apenas na cidade 4 foi observada uma incidência do dobro na transmissão vertical na cirurgia cesariana não-eletiva quando comparada ao parto vaginal.

\section{Discussão}

Desde 1994(,) os estudos têm comprovado que os anti-retrovirais (ARV) reduzem a transmissão vertical do HIV.1-3 A partir de então, nos países em que os ARV vêm sendo empregados, tal fenômeno tem sido confirmado.4,7 A TARV combinada e a cirurgia cesariana eletiva, quando empregadas conjuntamente, reduzem ainda mais a transmissão vertical.5,7,12 Conclui-se que com a identificação precoce da mulher portadora, a aplicação oportuna da TARV, com conseqüente queda dos níveis de carga viral materna (no sangue e nas secreções cervicovaginais) e, a menor exposição do recém-nascido ao HIV (via de parto adequada e não-amamentação), levam a melhores resultados. 1-12

O presente estudo comprova ter havido, ao longo do período, um aumento do diagnóstico sorológico para o HIV na população pesquisada, observando-se do período 1996 a 1999 ao período 2000 a 2003 um incremento de $40 \%$ nos dados provenientes dos prontuários médicos e um aumento de maior expressividade $(674 \%)$ entre as entrevistadas (componente prospectivo). Isso sinaliza ter havido uma resposta positiva da população-alvo (gestantes e cuidadores) a três grandes intervenções encabeçadas pelo Ministério da Saúde: o PHPN em 2000,16 o Projeto Nascer-Maternidades em 2002,18 e duas campanhas específicas sobre o tema, enfocando gestantes em 1999 e profissionais de saúde em 2002. Ao se analisar, porém, a qualidade da assistência dispensada a essas mulheres no pré-natal e no parto, tomando por referência alguns aspectos da "Linha de Cuidado", tais como o momento do diagnóstico da mãe, o número de consultas realizadas e a TARV instituída, deparamo-nos com uma realidade bem distante daquela que é recomendada pelo Ministério da Saúde. 13

Quanto ao número de consultas, a recomendação clássica na obstetrícia17 preconiza que toda gestante deverá comparecer mensalmente ao pré-natal até o sétimo mês de gestação, e que, no oitavo mês, o intervalo entre as consultas deverá ser quinzenal, e semanal, no último mês. Conclui-se, com isso, que cada gestante deveria realizar de 12 a 14 consultas, dependendo da semana de início de seu pré-natal. No caso das gestantes infectadas pelo HIV, consideradas população em condições de risco acrescido, esperase o cumprimento desse parâmetro, podendo haver casos a exigir um maior número de consultas. $\mathrm{E}$ isso vai além da recomendação básica do MS, que estipula um número mínimo de seis consultas de prénatal para uma gestante sem risco (PHPN).16 No presente estudo, ao se analisar essa informação no total da amostra e entre as entrevistadas, respectivamente, constatamos que esse número esperado de consultas foi realizado por apenas $1 \%$ e $11 \%$ das gestantes.

Ao verificarmos que a quase totalidade das mulheres não pôde cumprir o número de consultas preconizadas pela obstetrícia para uma gestante sem risco, o que dizer do cumprimento de todas as demais recomendações da "Linha de Cuidado" especializado 13 preconizada para as gestantes portadoras do HIV e seus bebês? Segundo os resultados, tanto no total da amostra quanto entre as entrevistadas, cerca de $10 \%$ das gestantes não tiveram acesso a sorologia para o HIV antes do parto e, dentre as que foram diagnosticadas, cerca de $39 \%$ (no total da amostra) e $30 \%$ (das entrevistadas) sequer usaram o AZT oral. O AZT injetável e em solução oral instituídos nas parturientes e nos recém-nascidos, respectivamente, constitui medicação com caráter de emergência que se destina a proteger a criança do HIV presente no sangue e nas secreções cervicovaginais da parturiente. Essa proteção só se concretiza quando o tempo preconizado de uso do AZT na parturiente é observado, e a instituição do AZT no recém-nascido obedece ao tempo pós-parto preconizado.1,13 O presente estudo assinala que, apesar de diagnosticadas, parte das parturientes não receberam AZT injetável; que apenas uma minoria teve acesso a essa medicação desde o início do trabalho de parto; e que quase $10 \%$ dos recémnascidos saíram da maternidade sem receber o AZT em solução oral. É importante lembrar que esses 
resultados foram observados em instituições reconhecidas como sendo de referência para o parto da população em estudo, localizadas em capitais brasileiras.

O momento do parto, em vários estudos, 5,7,12 tem sido apontado como a ocasião em que ocorre a maior parte da transmissão do HIV de mãe para filho e, por essa razão, os fatores obstétricos são determinantes para essa forma de transmissão. Vários outros estudos ${ }^{7}$ apontam a ruptura prolongada das membranas amnióticas como importante fator de risco para a transmissão vertical do HIV, tornando perfeitamente compreensível ser a CCE importante fator de proteção da transmissão vertical do HIV.5,12 Neste estudo, ao se observar as condições das membranas amnióticas por ocasião do parto, constata-se que $11 \%$ das mulheres permaneceram na instituição-referência com as membranas amnióticas rotas por mais de quatro horas, ou seja, tiveram seus bebês submetidos a risco acrescido de aquisição do HIV. Quanto à duração do trabalho de parto, $19 \%$ das parturientes estiveram aguardando a resolução de seu parto por período entre seis e 72 horas. Observamos ainda que, apesar da recomendação de uso do partograma no acompanhamento do trabalho de parto, essa informação não estava disponível em $12 \%$ dos prontuários médicos. O partograma é um recurso que possibilita documentar, em qualquer parturiente, a evolução do trabalho de parto, diagnosticar alterações, e indicar a adoção de conduta(s) apropriada(s), evitando ainda intervenções desnecessárias. 19

Prematuridade, sistema imunológico imaturo, nutrição fetal e amamentação são conhecidos como importantes fatores de risco para a criança, na transmissão vertical do HIV.4,6,7 Com relação ao risco de transmissão pela amamentação, um estudo de metanálise demonstrou ser esse um risco adicional, que se renova a cada exposição da criança ao peito e que se situa entre 7 e $22 \%$, o que equivale a dobrar o coeficiente de transmissão vertical do HIV.4,6,7 Os resultados do presente estudo, quanto ao tipo de leite fornecido ao recém-nascido, revelam que $10 \%$ das crianças foram expostas ao risco adicional conferido pela amamentação, observando ainda ter havido, dentro da instituição, amamentação cruzada de dois recém-nascidos.

A associação entre baixo peso e maior risco de infecção por transmissão vertical tem sido referida. ${ }^{7}$ Por sua vez, o baixo peso ao nascer tem sido associado às condições de infecção materna. ${ }^{7} \mathrm{No}$ presente estudo, a metade dos recém-nascidos exigiram cuidados especiais por terem nascido fora da faixa de peso normal. Também mereceram cuidados especiais $4 \%$ dos recém-nascidos que nasceram em asfixia, relacionada provavelmente a prematuridade ou parto traumático, dentre outras causas.

Do total da amostra, verificamos que $46 \%$ das mães não retornaram ao serviço, não sendo possível estabelecer o diagnóstico sorológico para o HIV de suas crianças. Tais perdas variam de $0 \%$ a $56 \%$ nas cidades incluídas no estudo. Nas perdas, assim como em outros parâmetros, não houve homogeneidade entre os serviços assistenciais de cada cidade, e tais diferenças não foram detalhadas neste artigo.

O coeficiente de transmissão vertical do HIV de $5,6 \%$ mostrou variação expressiva entre as cidades (de $2,9 \%$ a $7,5 \%$ ) e conforme o tipo de parto (de $2,6 \%$ na CCE a $8,4 \%$ no PV). A cidade 4 foi a que melhor expressou o esperado. Ou seja, coeficiente de transmissão vertical do HIV maior (10\%) quando o parto se processou em situação de risco acrescido para a mãe e seu recém-nascido (cirurgia cesariana não-eletiva) e a proteção conferida ao recém-nascido pela cirurgia cesariana eletiva (coeficiente de transmissão vertical do HIV=0\%). Nas cidades 1,2 e 3 os coeficientes de transmissão vertical no parto vaginal foram, respectivamente, $7 \%, 17 \%$ e $9 \%$, enquanto na cidade 4 esse coeficiente foi $5 \%$. Embora em todas as cidades participantes o menor coeficiente de transmissão vertical tenha sido observado nas crianças cujo parto foi a CCE, esse coeficiente na cidade 3 foi $5 \%$, ou seja, o mesmo obtido na cidade 4 entre as crianças que nasceram por parto vaginal.

O expressivo número de perdas, além de todas as informações que refletem as precárias condições em que se deu à assistência à população objeto deste estudo, conclama gestores e profissionais de saúde a repensar sua prática e conjuntamente propor uma organização que garanta o funcionamento adequado do processo de trabalho para o alcance dos resultados desejados.

\section{Recomendações}

Foi construído um modelo que possibilite ampliar o conhecimento quanto à compreensão, a organização e a administração para o programa de redução da transmissão vertical do HIV e controle da doença materna, partindo de uma proposta formulada por Ewart20 (Figura 1).

Esse modelo proposto, versão adaptada do modelo de Ewart20 (Figura 1), presta-se como guia para a organização, administração e monitoramento do Programa. Partindo-se da pergunta "O Programa proposto para a prevenção da transmissão vertical do HIV e controle da doença materna é efetivo?", logo 
nos vem como resposta que as intervenções protetoras (TARV, cesárea eletiva, não-amamentação, entre outras) estão bastante comprovadas e estabelecidas na política brasileira. Quanto à pergunta seguinte, "As metas propostas são factíveis, epidemiologicamente falando?", a resposta está vinculada à primeira, ou seja, os achados cientificamente comprovados só serão observados por aqueles que tomem a decisão de identificar e corrigir obstáculos e falhas encontrados em sua realidade local. É importante lembrar que as estratégias para uma ação eficaz, evidentemente, serão diferentes em cada contexto local, visto serem as condições disponíveis da estrutura e do processo diferentes. É nesse ponto que a instância administrativa local pode e deve usar de toda sua autonomia e criatividade para empregar os recursos que lhe são peculiares, de forma que o mesmo resultado possa ser alcançado em qualquer local do País. Indaga-se ainda "Os gestores e profissionais de saúde envolvidos estão motivados? Os obstáculos foram negociados?" Sabe-se que os melhores resultados são obtidos quando profissionais, gestores e usuários entendem as propostas formuladas e compartilham decisões. Estabelece-se a partir de então um compromisso entre as partes e a divisão de tarefas que cabe a cada um executar. Para a instância gerencial, duas questões se impõem: O Programa está organizado/administrado de forma adequada? Os recursos estão disponíveis no local em que deveriam? Embora estejam sob a responsabilidade das Coordenações de DST/AIDS a organização e a administração do Programa, é imperioso lembrar que essa responsabilidade deve ser compartilhada com a Atenção Básica, com as Coordenações de Saúde da Mulher e da Criança, e com os gerentes das instituições envolvidas. Caso contrário, o êxito esperado estará indubitavelmente comprometido.

O estabelecimento dos serviços como referência, funcionando em rede e não mais de forma isolada, é fundamental para a adequada assistência dessa população, por se tratar de pessoas em condição de risco acrescido, cabendo ao serviço de saúde, pela adequada vigilância, evitar a instalação do risco. É necessário que a concepção de serviço de referência esteja institucionalizada, e não mais calcada em pessoas de boa vontade, visto que a qualidade do serviço e, conseqüentemente, os resultados dependem da ação de todos. A organização assim proposta permite administrar e monitorar adequadamente as ações, distribuindo e redistribuindo os recursos conforme a necessidade identificada.

Finalmente, o sucesso do programa consiste em cobertura máxima de gestantes rastreadas para o HIV, facilidades garantidas para o processamento

\section{Figura 1}

Diagrama-Guia para identificação de pontos críticos e programação

\begin{tabular}{l|l} 
O Programa proposto de \\
Prevenção da transmissão \\
vertical (TV) do HIV e \\
controle da doença \\
materna é efetivo?
\end{tabular}

Fonte: adaptado do modelo proposto por Ewart HE. J R Soc Med 1991; 84: 488.20

laboratorial das amostras e retorno imediato dos resultados, referência para tratamento adequado, e seguimento das mulheres e seus bebês. Tal sucesso estará assegurado quando existir em todos os níveis de administração do programa o compromisso de monitorar permanentemente as condições em que estão se processando a estrutura e o processo, e qual(is) o(s) resultado(s) obtidos a partir dessas condições. Por outro lado, o processo de avaliação se completa com a divulgação dos resultados, de forma regular, para todas as instâncias envolvidas, motivando com isso gestores, profissionais de saúde e usuárias a cumprirem, cada um(a), o que lhes cabe para o satisfatório resultado que se deseja alcançar. O Programa Brasileiro de Prevenção da Transmissão Vertical do HIV e Controle da Doença Materna revela-se frágil no que diz respeito à sua organização, administração e avaliação nos serviços de saúde. A falta de organização dos serviços de saúde constitui um dos componentes da vulnerabilidade apontados por Mann e Tarantola, ${ }^{21}$ que se somam a aspectos individuais e sociais da pessoa. A carência da prática salutar de avaliação, possibilitando rever a organização e a administração dos serviços de saúde, e a instituição de ações cabíveis na estrutura e/ou no processo de trabalho quando necessário, não tem permitido ao Brasil contemplar, em todo o território nacional, coeficientes de transmissão vertical em patamares, perfeitamente factíveis, de $2 \%$ ou abaixo desse nível. 


\section{Referências}

1. Connor EM, Sperling RS, Gelber R, Kiselev P, Scott G, O'Sullivan MJ, VanDyke R, Bey M, Shearer W, Jacobson RL, Jimenez E, O'Neill E, Bazin B, Delfraissy J-F, Culnane M, Coombs R, Elkins M, Moye J, Stratton P, Balsley J, for the Pediatric AIDS Clinical Trials Group Protocol 076 Study Group. Reduction of maternal-infant transmission of human immunodeficiency virus type 1 with zidovudine treatment. N Engl J Med 1994; 331: 1173-80.

2. Shaffer N, Chuachoowong R, Mock PA, Bhadrakom C, Siriwasin W, Young NL, Chotpitayasunondh T, Chearskul S, Roongpisuthipong A, Chinayon P, Karon J, Mastro TD, Simonds RJ, on behalf of the Bangkok Collaborative Perinatal HIV Transmission Study Group. Short-course zidovudine for perinatal HIV-1 transmission in Bangkok, Thailand: a randomised controlled trial. Lancet 1999; 353: 773-80.

3. Wade NA, Birkhead GS, Warren BL, Charbonneau TT, French T, Wang L, Baum JB, Tesoriero JM, Savicki R. Abbreviated regimens of zidovudine prophylaxis and perinatal transmission of the Human Immunodeficiency Virus. N Engl J Med 1998; 339: 1409-14.

4. Newell M-L, Gray G, Bryson YJ. Prevention of mother-tochild transmission of HIV-1 infection. AIDS 1997; 11 (Suppl A): S165-S72.

5. The International Perinatal HIV Group. The mode of delivery and the risk of vertical transmission of Human Immuno-deficiency Virus type 1 - A meta-analysis of 15 prospective cohort studies. N Engl J Med 1999; 340: 977 87.

6. The Italian Register for HIV Infection in children. Human Immunodeficiency Virus Type 1 infection and breast milk. Acta Paediatr 1994; 83 (Suppl 400): 51-8.

7. WHO (World Health Organization), Joint United Nations Programme on HIV/AIDS (UNAIDS). HIV in pregnancy: a review. Genebra; 1999. p. 1-66.

8. Ministério da Saúde. Secretaria de Assistência à Saúde. Programa Nacional de Doenças Sexualmente Transmissíveis e AIDS: considerações gerais do binômio: HIV/AIDS e gravidez. Brasília (DF); 1995.

9. Lei Federal n. ${ }^{\circ} 9.313$, de 13 de novembro de 1996. Diário Oficial da União [DOU] 1996 (22) 14 nov.

10. Ministério da Saúde. Secretaria de Políticas de Saúde. Coordenação Nacional de DST e AIDS. Guia de tratamento clínico da infecção pelo HIV em adultos e adolescentes. Brasília (DF); 1998.

Recebido em 28 de agosto de 2005

Versão final apresentada em 3 de novembro de 2005

Aprovado em 5 de dezembro de 2005
11. Ministério da Saúde. Secretaria de Políticas de Saúde. Coordenação Nacional de DST e AIDS. Guia de tratamento: recomendações para a profilaxia da transmissão maternoinfantil do HIV e terapia anti-retroviral em gestantes. Brasília (DF); 2001.

12. Thome C, Patel D, Fiore S, Peckham C, Newell M-L and Members of the European Collaborative Study. Mother-tochild transmission of HIV infection in the era of highlya active antiretroviral therapy. Clin Infec Dis 2005; 40: 45865.

13. Ministério da Saúde. Secretaria de Vigilância em Saúde. Programa Nacional de DST e AIDS. Recomendações para a profilaxia da transmissão materno-infantil do HIV e terapia anti-retroviral em gestantes. Brasília (DF); 2004.

14. Ministério da Saúde. Secretaria de Atenção à Saúde. Departamento de Ações Programáticas Estratégicas. Área Técnica de Saúde da Criança. Manual de cuidados com o recém-nascido. Brasília (DF); 2005. [no prelo].

15. Ministério da Saúde. Secretaria de Políticas de Saúde. Área Técnica da Saúde da Mulher. Assistência pré-natal: manual técnico. 3. ed. Brasília (DF); 2000.

16. Ministério da Saúde. Portaria GM/MS nº 569 de 01 de junho de 2000. Diário Oficial da União [DOU] 2000 jun 8; (110) Séc E.

17. Rezende J, Montenegro CAB. Obstetrícia fundamental. 9. ed. Rio de Janeiro: Guanabara; 2003.

18. Ministério da Saúde. Portaria GM/MS nº 2.104, de 19 de novembro de 2002. 1. Diário Oficial da União [DOU] 2002 nov $21 ;$ (225).

19. Ministério da Saúde. Secretaria de Políticas de Saúde. Área Técnica da Saúde da Mulher. Parto, aborto e puerpério: assistência humanizada à mulher. Brasília (DF); 2001.

20. Ewart HE. The audit of cervical cytology screening programmes: discussion paper. J R Soc Med 1991; 84: 48890.

21. Mann JM, Tarantola DJM, editors. AIDS in the World II. The global AIDS policy coalition. New York: Oxford University Press; 1996. 